\title{
Program on Building Positive Self-Concept in Girls to Suppress the Number of Early Marriages in Pengotan Village ofBangli, Bali
}

\author{
Made Diah Lestari ${ }^{1}$, Ni Putu Natalya ${ }^{1}$, Indri Oktavia Rospita ${ }^{1}$, Wayan Citra Wulan Sucipta Putri ${ }^{2}$, Ni \\ Made Dian Sulistiowati ${ }^{3}$ \\ ${ }^{1}$ Psychology Study Program, Medical Faculty \\ Udayana University \\ Bali, Indonesia \\ mdlestari@unud.ac.id \\ ${ }^{2}$ General Medical Study Program, Medical Faculty \\ Udayana University \\ Bali, Indonesia \\ ${ }^{3}$ Nursing Science Study Program, Medical Faculty \\ Udayana University \\ Bali, Indonesia
}

\begin{abstract}
Early marriage is a phenomenon found in many countries, particularly in countries with high levels of poverty. Most of the victims are girls. Early marriage robs themtheir opportunity for self-development. At the community level, early marriage brings pressure to the development of human resources, increases the dropout rate, and triggers poverty. Early marriage is driven by various factors, such as the family's attempts to maintain their financial viability, family and peer pressure, early marriage being used as a means of controlling girls' sexual behavior, and due to socio-cultural conditions. In Bali, one of the practices of early marriage caused by economic pressures, family, and culture is found in the village of Pengotan in Bangli. This program is a preventive effort that aims to increase the positive assessment of local girls against themselves to reduce the number of early marriages. If one has a positive self-concept, they will appreciate themselves more and will certainly be appreciated by others. This program realized in the form of training was given to girls from grade fifth and sixth of elementary school. This age group falls into the category of transition age from childhood to adolescent which is prone to change. Through this program, girls are expected to be aware of their existence, to appreciate their gender, realize that girls have equal opportunities to boys, and understand the breadth of skills and opportunities that girls can have. At the end of the program, there was increased knowledge shown by the significant difference between the average value of the pre-test and post-test. Participants were satisfied with the program that they had followed. Changes in attitudes and behavior were then measured during one year after the program indicated by the number of girls who continue their study at school and the early marriage rate. Evaluation of attitudes and behaviors were conducted by interviews.
\end{abstract}

Keywords: early marriage, girls, positive self-concept, prevention program.

\section{INTRODUCTION}

Early marriage is an issue in almost all parts of the world. Its victims are mostly girls. Bayisenge (2010) mentions that there are many factors which lead to early marriage, among which are families efforts to maintain their economic viability, early marriage being used as a way to protect girls and to control girls' sexual behavior, family and peer pressures, conflicts and civil wars, socio-cultural factors and values that apply in some local cultures. In some cultures, there is a tendency for families to arrange the marriage of their girls soon after their akil baligh (becoming an adolescent). This culture is in fact still applied in some areas although there has been a development in human civilization. In a sum, early marriage is a violation of girls' rights that restrict their freedom and reduce the opportunity for self-development. At the community level, early marriage brings pressure to the development of the quality of human resources in a particular 
area and increases the dropout rate which is believed to be associated with an increase in poverty and a decrease in the welfare in both economic and psychological aspects. Early marriage is also a threat to women's reproductive health.

Regardless of the reasons, early marriage obviously leads to negative impacts both on the individual and the family, the next generation, and community. In a case of early marriage, marriage is not a celebration depicting joy; instead, it is a sacrifice of the rights and freedoms of individuals, and in many communities, early marriage at times puts at stake the economic viability of households that are part of the cultural values believed by the local community.

Early marriage refers to a formal or informal wedding; in this case, a young woman living with her partner before she reaches the age of 18 (UNICEF, 2005). According to United Nation Population Fund (in Bayisenge, 2010), early marriage is also called child marriage, which is any form of marriage by young women under the age of 18, before they are biologically and psychologically prepared in carrying out the responsibilities of marriage and parenthood. In reality, the minimum age for a person to get married which is deemed appropriate in some countries are so varying and cannot be fully limited to the two definitions above. Ironically, the minimum age is set lower than that set by UNICEF. If further investigated, among countries in Asia alone there are various minimum ages. The applicable laws in Indonesia stipulate 16 as the minimum age of a person to get married; it means that the minimum age of 18 years old set by UNICEF is not strong enough to govern the practice of early marriage in Indonesia. Malaysia implements two applicable minimum ages, one is set by the state and the other one is by the religion. Iran sets 13 as the minimum age, while China, Bangladesh, and Singapore set above 18 years old as the minimum age. The figuresare more varied across the continents, in Asia, Europe, America, and Africa. Indeed, these minimum ages should not be a point of debate and an issue; what should be the subject is how to reduce the number of early marriages and also how to overcome the negative impacts.
Based on the data from the United Nation Development of Economic and Social Affairs (UNDESA), Indonesia was ranked 37 in the world and the second in Asia after Cambodia in terms of the early marriage rate. The average of childbirths by adolescents aged 15-19 years also increased. In 2007, there were 35 per 1,000 adolescents, and then the figure increased in 2012 to 45 per 1,000 adolescents (www.metronews. com, July 12, 2013). In this program, early marriages due to pregnancy and risky sexual behavior are not discussed further. The discussion covers the early marriage caused by economic pressure, family, and the prevailing values and cultures in a region.

In Bali, one of the practices of early marriage due to economic pressures, family, values, and culture, is found in the village of Pengotan in Bangli. Early marriage in this village is assumed to be one of the causes of high rates of poverty. The number of poor households is equal to $56 \%$ of the 924 families. Approximately $92 \%$ of the poor households did not complete primary school or its equivalent. Early marriage gave rise to high school dropout rates and leads to poverty. A mass marriage ceremony in a local village temple which is held twice a year is one of the uniqueness of this traditional village that is actually a symbol of the legitimacy of early marriage (Muninjaya, 2012). Gender inequality and very limited opportunities for girls to get an education and work also lead to early marriage. Parents prefer boys to girls. This is mostly found in the patriarchal culture that values male offspring higher than female ones. Girls of this village rarely marry a youth outside the village. Possibly, it is because of their very limited mobility. This condition causes marriages between young people in this village quite prominent. This condition has also been identified as the main factor that leads to early marriage (between 14 and 18 years old). Educational facilities were very limited; in this village, there are only three primary schools and one Junior High School. It seemed that Pengotan people have not understood the importance of education for their progress there. For them, high school is not something that is essential if access to jobs is believed to be very limited. 
If the real conditions above are examined, the prevention of early marriage should be comprehensive. On the macro side, the government should pay attention to equity in education with the provision of facilities and schools. Access to nearby schools has to be facilitated so that educational opportunities become more widespread. Education is the foundation for the next stage, which is looking for a job. Continued cooperation between the government, communities, and businesses to create jobs that range in accordance with the needs of local communities is required. Of course, the business world and jobs are opened by maximizing the demographic potential owned by the Pengotan Village of Bangli.

On the micro level, it is necessary to empower women to form a positive self-concept in themselves. Positive self-esteem will make women appreciate themselves and gain recognition from the community. Lack of recognition for the girls in the middle of the cultural hegemony of patriarchy in the village of Pengotan in Bangli makes the world of women becomes narrower. If girls have a positive selfconcept, they will have confidence in the ability and opportunity they have, instead of doing their domestic roles only. Through positive selfassessment, girls will have an insight into the various possibilities that they can have after primary school, so it is assumed to be able to reduce the number of early marriages. This program focuses on the handling of the micro level, i.e., an increase in positive self-concept in girls in the village of Pengotan in Bangli.

\section{METHODS}

This program is a preventive effort aimed at forming a positive self-concept in local girls to reduce the number of early marriages. The program which takes the form of community service program is the training that was given to girls in the fifth and sixth grade of elementary school. The program includes material for recognition of sex and gender, the introduction of the body, sexual organs, and how to take care of them, self-concept, motivation, recognition of skills and opportunities for females in education and employment. Through this program, girls are expected to be aware of their existence, to appreciate their gender without diminishing respect for men, to realize that girls have the same opportunity, rights, and obligations as what boys have, to understand the breadth of skills and opportunities that can be owned by girls, and the building of behavior for boys to respect girls. This program can not stand alone to reduce the number of early marriages in the village. A number of programs have been carried out previously as to support this program, such as the intervention in the field of education by training teachers and the movement of foster parents. Intervention in the field of an economy was also carried out by providing entrepreneurial training and the provision of working capital for the community so that skills and employment opportunities increased (Muninjaya, 2012).

The title of this program is I AM PROUD of being A FEMALE. This program which took the form of training used a variety of delivery methods, such as discussions, group activities, field assignment with photo voice media, and art activities. The program consists of three meetings, namely every Saturday for three weeks.

\section{A. Design of the Program}

This program consists of 6 materials, namely:

1. Aremen and women the same. The participants in this material have an understanding of gender and no gender is superior as well as everyone is equal.

2. Memory flashbacks of learning about gender from childhood. This section is helping participants give examples of how they absorb messages about gender roles, to consider these messages from a personal and human rights point of view, and to improve critical thinking skills.

3. It is my body and I care about it. In this material, participants are introduced to parts of the body biologically and physiologically. When the participants know and understand the functions of parts of the body, a sense of responsibility to take care of them is expected to grow.

4. Sexual behavior, myths, and facts. This activity helps participants understand how to maintain sexual and reproductive 
health. It helps participants identify the correct information on sexual behavior.

5. Dare to dream. This activity helps participants to dare to dream about their goals.

6. Opportunities also belong to females. Gaining knowledge related to various roles in the community. These roles are categorized based on sex. However, sometimes the role can flexible. This activity gives an understanding that there is no difference between the roles of males and females. Females have the same opportunities as males.

\section{B. The Subject of the Program}

The target subject for this program was a group of girls from grade fifth and sixth of elementary schools, by taking into account the following matters:

1. The maximum school age that can be reached, given that the average school age isup to elementary school age.

2. Preparing them to enter teenage years and post akil baligh (becoming an adolescent) which is the age range of marriages in Pengotan village of Bangli (14-18 years old)

The total number of participants was 30 girls spread over three Elementary Schools in Pengotan.

\section{Evaluation of the Program}

An evaluation of the program was carried out by observing four things, namely:

1. Knowledge. An evaluation was in the form of pre-test and post-test to see changes in the participants' understanding related to knowledge of self and gender. The indicator of success was seen from the significant increase in the average value of the pre-test and post-test.

2. Process. Evaluation of satisfaction of the program by the participantsby filling out the form about the participants' satisfaction with the activity. Indicators of success were seen from the participants' satisfaction with the content, the quality of the presenters, the quality of the knowledge, and a sense of excitement while attending the program.
3. Attitude. Evaluation of the changes in attitudes associated with the intention to continue both formal and informal education after graduating from elementary school, conducted one year after the program. Indicators of success were seen from $50 \%$ of the participants who had the intention to continue to formal and informal education which was determined through interviews within one year after attending the program.

4. Behavior. An evaluation of the number of participants who decided to get married at an early age which was conducted one year after the program including the reasons. The indicator of success was seen from $50 \%$ of participants who were not married at an early age one year after attending the program. This figure was determined by follow-up interviews with the participants for one year after the program.

\section{RESULTS}

Based on the results of observations of each material presentation session, some interesting facts were found. The following are the findings during observations at each session:

1. Are men and women the same. In this material, it was found that girls tend to judge that men and women are different, not only physically, but also in terms of characters and the opportunity to learn and work. When they were asked to discuss and write down the differences between men and women, it appears that characterssuch as strong, independent, not easy to cry, tough, grumpy are possessed by men. Gentle, patient, and whiny,on the other hand,are some of the characters possessed by girls. Participants also assumed that boys have the opportunity to work outside the home, while girls work at home. Boys like playing toy cars while girls like playing with dolls.

2. Memory flashbacks of learning about gender from childhood, this session covers the materials with the topic "it's my body and I care about it", and "sexual behavior myths and facts". This session was an interesting session for the participants because they were encouraged not to be shy when talking about 
sexuality. They were pleased to be able to know how to take care of their body when growing up later.

3. Dare to dream and opportunities also belong to girls. Basically, the participants already knew about the roles that exist in the community. Through role-play and fairy tale cartoons, the participants knew that the role could be flexible between men and women. Women can do men's hobbies and work and vice versa. In the last session, the participants expressed their goals. Most aspired to be a teacher. Some of them wanted to become a policewoman, a cook, and also a doctor. They were committed to reachingtheir goals and were given the opportunity to take pictures with attributes that fit their goals. In this session, the participants also visited an office and had a chance to see how female workers work everyday at the office.

In terms of knowledge, it can be seen that there is a significant increase in knowledge related to self and gender after the program compared to that before the program ( $\mathrm{sig} .000, p<.005$ )

It shows that participants are able to take in, understand, and remember the training materials provided. At the time of the pre-test, all participants still assumed that men were stronger than women; the characters of tough, independent, and brave were only possessed by the men and only men who could work outside the home while women worked only at home. Their knowledge related to sexual and reproductive health was still limited. Basically, they already knew what menstruation is, but did not fully understand about parts of the body that should be paid attention to when they grow up.

The results of the evaluation over the satisfaction of the program showed that $70 \%$ of the participants really liked the programs that they had followed, and 30\% liked the program. A total of $93 \%$ of the participants were happy when attended the program. In terms of the quality of the knowledge that was shared and also the quality of the presenters, the participants considered that the required material or knowledge that had been presented was categorized as good and very good. They also thought that the quality of the presenters fell into the category of good and very good. Through an assessment of the quality of the shared knowledge, it could be seen that $83 \%$ of the participants considered that knowledge that had been shared was very good. In terms of the quality of the presenters, as many as $77 \%$ of participants rated that the presenters were very good in presenting the material.

In terms of attitude and behavior evaluation, $100 \%$ of the participants have decided to continue their education 1 year after the program. The similar program was conducted 1 year later in order to enhance family support in girls education and well-being.

\section{DISCUSSION}

Through this program, it appears that assessment by girls of Pengotan Village of Bangli associated with roles of men and women is still very limited and tends to stereotype. Girls tend to judge boys as stronger than girls. Some girls also judge that a father is a figure who works outside the home and supports a family, while the mother's or women's mobilization is limited and only in doing house chores. Olson \& Defrain (2003) revealed that the traditional roles of men and women were divided into the instrumental role and the expressive role. Men take the instrumental role in which they have a duty to make a living and working outside the home. Women take the expressive role in which they have a duty to take care of the children and do household chores. The view that divides the roles of men and women separately gained sharp criticism in the era of feminism due to the idea that the women are the helpless and do not have the same opportunities as men. The view of the feminism that sees women as central the same as the men have ultimately changed the traditional concept related to the role of men and women. In recent times women have equal opportunity to work and have a career outside the home life without having to forgo their nature as women. This stereotype was evident in the pre-test and the first session activities.

Certain characteristics are also identified as the characteristics of girls that are not possessed by boys, and vice versa. Basically, some experts 
revealed that there are indeed trait patterns that are different between men and women. For example, in terms of building communication, it appears there is a trait that differs between men and women. Men are said to be more competitive and active, whereas women show more affiliation and attachment with others (Olson \& Defrain, 2003). On the other hand, some experts also see no gender differences in terms of the characteristics possessed by men and women. If it is said that girls are easier to express emotions and emotionally more mature, the research conducted by Natalia (2014) found that there is no difference in the level of emotional maturity between men and women.

Gender is a central aspect of human identity and has been developed through the developmental stages. One aspect of gender identity is self-perceived gender typicality. Gender typicality is a term to identify how close is individual perceives himself similar to their sex (Egan \& Perry in Patterson, 2012). The concept of gender typicality is similar to the concept of gender conformity. Previous studies regarding the gender typicality focused on negative outcomes associated with low self-perceived gender typicality (e.g., low self-esteem), on the other hand, Patterson (2012) found that low selfperceived gender typicality also related to flexible gender role attitudes. In a sum, it is necessary for an individual to have a flexible attitude toward gender role.

Sexual education, ranging from the understanding of parts of the body, how these parts develop with the increasing age basically is not something taboo anymore to be discussed with children. With a fun approach, discussions, films, and group work, the children were able to understand with ease and no longer hesitated to discuss sexuality issues within the health and scientific scope. In the post-test, some children were not shy anymore to answer the last question asked about what were the parts of their body that grow as they grow older. The answers like breast, body, genitals, were written without hesitation.

Dream is a fun topic to discuss. In terms of career development at children's age, Super and Ginzberg (in Seligman, 1994) mention that children aged between 10-12 years old and will enter adolescence, usually choose professions that they prefer to serve their ideals. Things that they like depending on their surrounding. A teacher was the most desirable profession chosen by them because a teacher is a profession that they in their daily life and teachers have become their role models. Doctors and police officers were also the ideals selected by some of the children because doctors and police officers are a variety of positive ideals and accepted by their society. Cook as a dream profession was a surprising result for culturally this profession is not often cultivated by the local people there. Cook as a chosen ideal was influenced by the reality TV show that presents a cooking competition among child cooks.

Adolescence is the most critical period for female identity development. It is a crucial period for self-esteem formation (Kling, Hyde, Shower, \& Boswel, in Steese, Dollette, Phillips, Hossfeld, Matthews, \& Taormina, 2006). Therefore program on building a positive self-concept among girls is a impressive program. Lower levels of self-esteem have been correlated with several negative outcomes, including early marriage, substance abuse, depression, social anxiety, alienation, suicide, and juvenile delinquency (Gurney in Patterson, 2012).

Based on the results of the evaluation of the program it was found that the participants were happy during the program. The post-test results showed a significant increase in the level of knowledge. Follow-up interviews with participants and families and forming a family assistance group were needed to assess the success of the program in terms of changes in attitudes and behavior. The family assistance group was formed by adopting the concept of dasa wisma as a supporting group for the villagers and to monitor the progress of the participants in terms of education, employment, opportunities for females, and the control of early marriage rate in Pengotan Village, Bangli.

\section{APPENDIX}

Table 1.

Mean values of the Pre Test dan Post Test

\begin{tabular}{lllll}
\hline & Mean & N & SD & SE Mean \\
\hline Pre Test & 32.333 & 30 & 13.308 & 2.429 \\
Post Test & 66.666 & 30 & 25.641 & 4.681 \\
\hline
\end{tabular}


Table 2.

Paired Sample Test

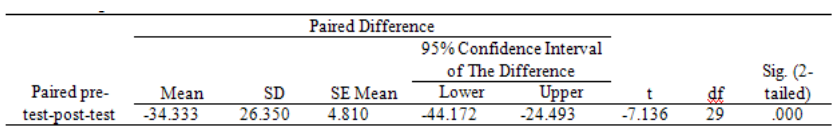

Table 3.

Evaluation of the Process of Participants' Satisfaction of the Program

\begin{tabular}{|c|c|c|c|c|c|c|c|}
\hline \multicolumn{8}{|c|}{ The degree of Satisfaction of Program } \\
\hline \multicolumn{2}{|c|}{ Dislike } & \multicolumn{2}{|c|}{ Like } & \multicolumn{2}{|c|}{ Really Like } & \multicolumn{2}{|c|}{ Etc } \\
\hline $\mathrm{F}$ & $\%$ & $\mathrm{~F}$ & $\%$ & $\mathrm{~F}$ & $\%$ & $\mathrm{f}$ & $\%$ \\
\hline 0 & 0 & 9 & 30 & 21 & 70 & 0 & 0 \\
\hline \multicolumn{8}{|c|}{ What is Felt During the Activity } \\
\hline \multicolumn{2}{|c|}{ Sad } & \multicolumn{2}{|c|}{ Happy } & \multicolumn{2}{|c|}{ Very Happy } & \multicolumn{2}{|c|}{ Etc } \\
\hline $\mathrm{F}$ & $\%$ & $\mathrm{~F}$ & $\%$ & $\mathrm{~F}$ & $\%$ & $\mathrm{f}$ & $\%$ \\
\hline 0 & 0 & 1 & 3 & 28 & 93 & 1 & 4 \\
\hline \multicolumn{8}{|c|}{ The Quality of the Knowledge Gained } \\
\hline \multicolumn{2}{|c|}{ Poor } & \multicolumn{2}{|c|}{ Good } & \multicolumn{2}{|c|}{ Very Good } & \multicolumn{2}{|c|}{ Etc } \\
\hline $\mathrm{F}$ & $\%$ & $f$ & $\%$ & F & $\%$ & $\mathrm{f}$ & $\%$ \\
\hline 0 & 0 & 5 & 17 & 25 & 83 & 0 & 0 \\
\hline \multicolumn{8}{|c|}{ The Quality of the Presenters } \\
\hline \multicolumn{2}{|c|}{ Poor } & \multicolumn{2}{|c|}{ Good } & \multicolumn{2}{|c|}{ Very Good } & \multicolumn{2}{|c|}{ Etc } \\
\hline $\mathrm{F}$ & $\%$ & $\mathrm{f}$ & $\%$ & $\mathrm{~F}$ & $\%$ & $\mathrm{f}$ & $\%$ \\
\hline 0 & 0 & 7 & 23 & 23 & 77 & 0 & 0 \\
\hline
\end{tabular}

\section{ACKNOWLEDGMENT}

I AM SO PROUD of being A FEMALE Program was supported financially by Institute for Research and Community Services Udayana University. The authors also would like to express gratitude to all of the participants and Pengotan, Bali Village.

\section{REFERENCES}

Bayisenge, J. (2010). Early Marriage As A Barrier To Girl's Education: A Development Challenge in Africa. Phd. Thesis. Rwanda: National University of Rwanda.

Dallo, M., \& Greene, M.E. (2011).Addressing Early Marriage of Young and Adolescent Girl. USA: Youth Lens.

Indonesia Rated the Second in Terms of the Number of Early Marriage Among ASEAN Countries. (July 12, 2013). www.metronews.com. AccessedonFebruary 5, 2014. http://www.metrotvnews.com/life style/read/2013/07/12/917/167631/JumlahPernikahan-Dini-Indonesia-TerbanyakKedua-di-ASEAN
Muninjaya, A.A.G. (2012). Membangun Negeri dari Desa Program Desa Dampingan Unud. Indonesia: Udayana University.

Olson, D.H., \& DeFrain, J. (2003). Marriage and Family: Intimacy, Diversity, and Strength $\left(4^{\text {th }}\right.$ ed). New York: McGraw Hill.

Patterson, M.M. (2012). Self-Perceived Gender Typicality, Gender-Type Attributes, and Gender Stereotype Endorsement in Elementary-School-Aged Children.Sex Roles.67: 422-434.

Seligman, L. (1994). Development Career Counseling And Assessment. Indiana: Sage Publications.

Steese, S., Dollete, M., Phillips, W., Hossfeld, E., Matthews, G., \& Taormina, G. (2006). Understanding Girls' Circle As An Intervention On Perceived Social Support, Bodt Image, Self-Esteem. Journal of Adolescence. 41(161): 55 - 74.

The United Nations Children's Fund.(2001). Early Marriage Child Spouses. Italy: Merh Khan.

The United Nations Children's Fund. (2005). Early Marriage A Harmful Traditional Practice: A Statistical Exploration. New York: Division of Policy and Planning. 